\title{
Editorial: Of the Philosophies of Africa - Theory and Practice
}

Volume 8.1 of Culture and Dialogue is devoted to aspects of African thought and in particular philosophy, whether theoretical or practical. This issue has been generously guest-edited by Felix O. Olatunji, of Ladoke Akintola University of Technology and Osun State University, Nigeria.

As reflected in the selection of essays, the overall concern of this issue is not really to question whether there is such a thing as "African philosophy." Thankfully, for many, the answer to this question is simply provided in the significant and multifarious corpus of texts produced across the continent of Africa and its history. Of course, any question concerning "African philosophy," i.e. a specifically pan-African discipline with its own methods and forms, is partly different from that of "African thought" in general, for the latter includes not only processes of consciousness that reflect on the natural and human fields, but also practices whose very nature is to create or express specific cultural textures. Indeed, the choice of "African Thought" - rather than "African Philosophy" - in the title of this journal issue is a way of leaving the door open to thought-practices that would be considered as foreign or simply borderline to what is usually considered as philosophy by the Western establishment, that is, by those who have come to believe and persuade the rest of the world that the love of wisdom is the love of logos. For example, how practical, literary, or ethnological can philosophy be before it becomes something else? From this perspective, the question as to what constitutes philosophy "proper" within the context of Africa can understandably be, in itself, dismissed as a mere semantic one. This is not to say that endeavours to characterise, develop and renew a body of philosophical disciplines that is typically of Africa - African philosophy - is meaningless.

Philosophy as a thinking-process that develops within specific natural and human environments, or as awakening to modes of being or the emptying nature of things or even to their relational nature, counts as one of the fundamental ingredients that contribute to building a voice for others to listen to, learn from, and in turn be renewed. On this account, what can be more justified and even natural than to seek to think through one's own languages and customs? Of course, the histories of the countries and various regions and 
peoples of Africa partly shaped by their relationships with the Western world and Europe in particular constitute sizeably relevant circumstances to understand, endorse and pursue the will to develop specific modes of thought across the continent. But, as always, the question of identity is never an innocent one, whether as means of liberation, conquest, or reciprocity. As such, it can hardly be ignored, including when it comes to pondering on the cultural specificity of a philosophy, be it African or otherwise.

Again, the will to formulate an identifiable mode of thinking amounts, in particular circumstances that may be defined by history or geopolitics, to justifiably raising one's voice within a world of ten thousand voices. And only those who overlook or deliberately ignore the generative, relational nature of that human-bound facticity called identity will guide some of us to the threshold of the catacombs of illusionary origins or vertiginous ideals. Any form of continentalism that seeks to retrieve or impose such origins or ideals has the potential of becoming as dangerous as, if not more dangerous than nationalism, or any type of closurism on whatever scale. The will to raise one's voice should not become a will to power per se but should translate into a will to channel the constant fluctuations between identity and circumstances. This also means that such endeavour cannot be performed alone; that the ten thousand voices should find the will or be enabled to express their differences and similarities as way of guaranteeing what makes up the stuff of the world, that is, the non-dualistic dynamic of reciprocity. And what better term to designate this relational practice than the dialogue, even if the practice needs to be forced through in some circumstances that have created imbalances since the birth of humanity? When Kwasi Wiredu suggests "to think through in your own African language," he is not advocating any kind of cultural communitarianism; what is implied, rather, is to let identifiable voices express themselves through critical dialogue with, in this case, "some metropolitan language" albeit externally imposed in the course of history. Such an endeavour can nowadays take many shapes, theoretically as well as practically.

Africans are faced with a plethora of problems spanning instability and social disorder, value clashes, terrorism, public health conditions, and developmental crises; epistemological and metaphysical questionings that impact on the peoples' lives, ethnic and religious turbulences within its many nations, the struggle for freedom and democratic consolidation, or imbalances in gender-related policies, to name a few. The identity-bound challenge of an African thought in the making is, therefore, to formulate strategies and mechanisms both in theory and practice to deliver not only the peoples but also their governments from occlusion, ossification and anachronism. This is, indeed, to acknowledge and advocate the vital need for critical dialogue to allow for 
particular voices to be heard. Unavoidably and in light of their geopolitical and historical circumstances, the many African voices are calling for pathways to liberation and transformation from metropolitan and hegemonic worldviews that have hitherto partly undermined the possibilities of peace, progress and development on the continent. African philosophies and the many disciplines in the human and social sciences contribute to this struggle by situating, clarifying, and even creatively expressing the main human values of tolerance, openness and criticism that are required for an edifying effort against the coercive internal and external forms of colonialism on the continent. This effort towards an African renaissance must be dialogically self-generated to allow for any form of significant value-progress in African societies.

All fields of knowledge seek to impact on human behaviours and experiences through the building of ideas in relatio. Philosophy and the other cognitive disciplines and practices are no exception. Hence, the on-going and strengthening building of philosophy has gained primacy in the context of Africa as a way of raising its own voice on key issues pertaining to its cultures, histories and politics among others. Unavoidably, for better or for worse, this endeavour also incorporates a critical dialogue with Western worldviews, their conceptions of modernity including when it comes to appraising scientific and technological innovations.

Philosophies in contemporary Africa are not - or should not be - abstracting cognitive methods framed by Western models although, once again, engaging with the latter is a sine qua non condition for historical and geopolitical reasons. The philosophies of Africa now seek to constructively address the thoughts, behaviours and experiences of the African peoples with a view towards decolonisation, in other words, the eradication of that element of permanent imbalance that prevents any mutually edifying dialogue to take place. Decolonisation means developing a social order that allows for creative freedom and human dignity - a goal that can only be achieved by fostering reflection, pragmatism, rationality, and criticality towards both traditions and inherited values. Many African thinkers have already advocated in one way or another this kind of critical dialogical practice, both internally and externally, as a fertile ground for Africa's identity-formation, that is, for the voices of Africa to be heard. For Kwame Gyekye "Africans need to deal seriously with the ideas, values, practices and institutions that sub-Saharan Africa has received from other cultural sources so as to 'rediscover and resume our proper selves."' For Olusegun Oladipo, addressing Africa's identity crisis amounts to questioning "how Africans can achieve the goals of freedom and development without compromising their identity." Needless to say, this conception of African identity is not about retrieving and preserving eternally some alleged original, 
authentic cultural model. Identity here is in the making, that is, open to freedom and development but without giving itself up. Wiredu put it this way: "the answer to Africa's problem of identity in the contemporary world does not lie in a cultural traditionalism but in a critical and reconstructive self-criticism."

Thus, there is equally a need to move beyond views on the failures of Africa that hinge on the colonial influences. In this light, striking is the kinship between the dialogical attitude and the African endogenous idea of Ubuntu broadly construed in terms of non-dualistic interdependency of human beings (indeed, within and beyond the continent); a belief in a sense of common humanity that also rests on personal freedom and dignity of the self, personal recognition and self-fulfilment. At the heart of this form of humaneness is, therefore, the relation.

All the authors who have generously contributed to this issue on "African Thought and Dialogue" have addressed in their own different ways, whether theoretically or practically, facets of what it means to build identifiable voices within the infinite context of Africa, and this without being allured by the mermaids of easy essentialism or falling into the trap of passive nihilism. Authors include Felix O. Olatunji on "African Identity"; Wim van Binsbergen on "the Fundamental Unity of Humankind"; Abosede Ipadeola on "Women and the Project of Decolonization in Contemporary Africa"; Mohamed Turki on "Frantz Fanon, Humanism and Postcolonial Studies"; Kenneth Adewole Adesina on a "Template for Cultural Development in Africa"; Philip Ogochukwu Ujomu on "Africa's Crisis of Social and Political Order and the Significance of Ubuntu Human Values"; Gbenga Fasiku on "Phenomenality and Embodied Cognition in Yorùbá Thought System"; Paul K. Michael on "Youth Vulnerability and the Challenge of Human Development in Africa"; Michael O. S. Afolabi on "Identity Dilemmas of Western Healthcare in Africa"; and Peter F. Omonzejele on the "Culture of Baby Farming and Harvesting for Ritual Sacrifices in Nigeria."

As ever, we are immensely grateful for whatever invaluable support from our editorial team and members, and especially to those of you who have successfully promoted the Journal to your respective institutions and beyond as evidenced in the growing list of subscribers.

\section{Gerald Cipriani and Felix O. Olatunji}

